\title{
Expression of human HPRT mRNA in brains of mice infected with a recombinant herpes simplex virus-1 vector
}

(Gene therapy; Lesch-Nyhan syndrome; hypoxanthine-guanine phosphoribosyltransferase; mouse transcripts; RNase A mapping analysis; riboprobes)

\section{Thomas D. Palella ${ }^{a, e}$, Yuji Hidaka ${ }^{a, e}$, Larry J. Silverman ${ }^{\text {a,e }}$, Myron Levine ${ }^{b}$, Joseph Glorioso ${ }^{c}$ and William} N. Kelley ${ }^{\text {a,d,e }}$

Departments of ${ }^{a}$ Internal Medicine, ${ }^{b}$ Human Genetics, ${ }^{c}$ Microbiology and Immunology, ${ }^{d}$ Biological Chemistry, and ${ }^{e}$ The Rackham Arthritis Research Unit, University of Michigan Medical School, Ann Arbor, MI 48109 (U.S.A.)

\section{SUMMARY}

Complete deficiency of the purine salvage enzyme hypoxanthine-guanine phosphoribosyltransferase (HPRT) results in a devastating neurological disease, the Lesch-Nyhan syndrome. This disorder has been identified as a candidate for initial attempts at somatic cell gene therapy. We have previously reported the construction of a recombinant herpes simplex virus type 1 (HSV-1) vector containing human hprt cDNA sequences under the regulatory control of the viral thymidine kinase gene $(t k)$ [Palella et al., Mol. Cell. Biol. 8 (1988) 457-460]. Infection of HPRT ${ }^{-}$cultured rat neuronal cells with these vectors resulted in transient expression of human hprt. In this paper, we report the expression of human hprt mRNA transcripts in the brains of mice infected in vivo with this vector by direct intracranial inoculation. Human $h p r t$ transcripts were distinguished from endogenous mouse transcripts by RNase A mapping using riboprobes transcribed from human hprt cDNA. These initial studies demonstrate the transfer and transcription of a human gene in brain cells by direct in vivo infection with recombinant HSV-1 vectors.

\section{INTRODUCTION}

The purine salvage enzyme, HPRT, catalyzes the conversion of hypoxanthine and guanine to the mononuclcotides, IMP and GMP, respectively. A

Correspondence to: Dr. T.D. Palella, Department of Internal Medicine, University of Michigan Medical School, 1150 West Medical Center Drive, 5520 Medical Science Research Building I, Ann Arbor, MI 48109-0680 (U.S.A.) Tel. (313) 747-3413; $\operatorname{Fax}(313) 763-4151$. virtually complete deficiency of HPRT activity in humans causes the Lesch-Nyhan syndrome, a devastating disease in which overproduction of uric acid and severe neurological dysfunction occur (Seegmiller et al., 1967). There is no effective treat- 
ment for the behavioral manifestations in this ultimately fatal disorder. Furthermore, despite the dramatic functional consequences of HPRT deficiency, no anatomical structural changes are noted in the central nervous system of these patients. For these and other reasons, attention has been focused on the Lesch-Nyhan syndrome as one of the initial candidates for therapy by somatic cell gene transfer (Anderson, 1984).

Retroviral vectors containing human hprt gene sequences have been constructed by others (Miller et al., 1983; Chang et al., 1987). Mouse bone marrow cells infected with one of these constructs were transplanted into lethally irradiated mice. These infected bone marrow cells repopulated the hematopoietic cells of the recipient mice and transiently expressed human hprt (Miller et al., 1984). However, previous studies have shown that restoration of HPRT activity in the circulation by either exchange transfusion or bone marrow transplantation has no demonstrable effect upon the neurological disease (Edwards et al., 1984; Nyhan et al., 1986). Thus, it appears that the hprt gene will need to be targeted to cells of the central nervous system if somatic cell gene therapy is to be effective in treating the central nervous system manifestations of the Lesch-Nyhan syndrome.

We have previously reported construction of HSV-1 vectors (see Fig. 1) containing the human $h p r t$ cDNA under the regulatory control of the viral $t k$ promoter (Palella et al., 1988). Infection of HPRT-deficient cultured rat neuronal cells with these recombinant HSV-1 vectors resulted in transient expression of human hprt. We chose HSV-1 as the mediating vector for hprt gene transfer into neuronal cells because it is a neurotropic virus capable of establishing latent infection in neuronal cells (Baringer and Sworeland, 1973; Cook et al., 1974; Cook and Stevens, 1976). Additionally, HSV-1 can express mammalian genes inserted into its genome in a variety of culture systems (Shih et al., 1984; Tackney et al., 1984).

In this paper, we report expression of virally encoded human hprt mRNA in the brains of mice infected with these vectors by intracranial inoculation.

\section{MATERIALS AND METHODS}

\section{(a) Animals}

DBA/2J mice were purchased from Charles River Laboratories. In these experiments, males weighing approx. $25 \mathrm{~g}$ were used.

\section{(b) Materials}

Enzymes for DNA modification were purchased from New England Biolabs, Beverly, MA, RNase A and RNase T1 were from Sigma Chemical Co., St. Louis, MO., RNase inhibitor (RNasin), SP6 RNA polymerase, and DNase were from Promega Biotec, Madison, WI. [ $\alpha-{ }^{32}$ P] GTP was obtained from New England Nuclear, Boston, MA, nitrocellulose filter from Millipore Corp., Bedford, MA, and Eagle's minimum essential medium and fetal calf serum from Gibco Laboratories, Grand Island, NY. Methoxyfluorane was purchased from Pitman-Moore, Inc., Washington Crossing, NJ, and staphycoccal protein A (Igsorb) from the Enzyme Center, Malden, MA. All other reagents were of the highest grade commercially available.

\section{(c) Cell lines}

GM558 is a human lymphoblastoid cell line with normal HPRT activity (Human Genetic Mutant Cell Repository, Camden, NJ). Cell lines 904 and 905 are human lymphoblastoid cells deficient in adenine PRT activity. Both lines have normal levels of HPRT activity (Hidaka et al., 1987). GM558, 904 and 905 were maintained in RPMI 1640 supplemented with $10 \%$ fetal calf serum. VERO cells, used to produce stocks of viral vectors, were maintained in MEM containing Hank's salts and supplemented with $5 \%$ fetal calf serum.

\section{(d) Vectors}

Construction and characterization of the vector, HSV-HP40, which contains the human hprt cDNA within the viral $t k$ gene has been described previously (Palella et al., 1988) and is summarized in Fig. 1. Stock suspensions of virus containing $10^{6}$ pfu per $\mu 1$ were obtained from lysis of infected VERO cells. Viral suspensions were titered by a plaque assay on VERO cells. 


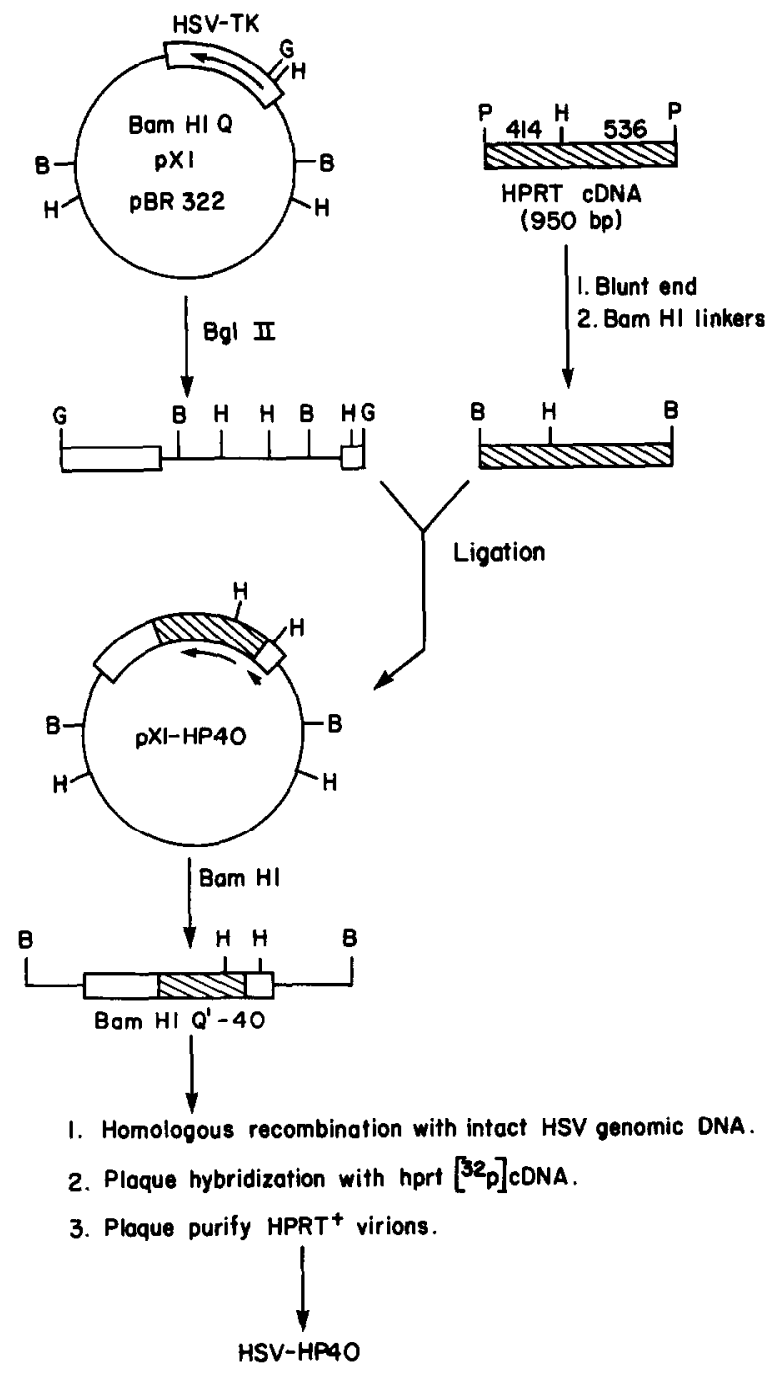

Fig. 1. Construction of chimeric HSV containing human hprt cDNA (Palella et al., 1988). HSV-HP40 has hprt cDNA in the correct orientation with respect to the $t k$ promoter. Drawings are not to scale. Abbreviations: B, Bam HI; G, BglII; H, HincII; P, Pst I.

\section{(e) Infection of animals}

Mice were anesthetized by methoxyfluorane inhalation. Ten to $20 \mu$ l of viral suspension $\left(10^{7}\right.$ to $2 \times 10^{7} \mathrm{pfu}$ ) were injected into each cerebral hemisphere by intracranial inoculation using a Hamilton syringe. The point of injection was chosen to introduce the viral suspensions into the area of the lateral ventricles slightly anterior to the mid-coronal plane. The exact position for injection to achieve inoculation into the ventricles was empirically determined in advance by the injection of dye.
Immediately after injection, animals were returned to their cages and allowed to feed and drink ad libitum. Mice were observed daily for illness or death. On days 2, 3, 5 and 7 after infection, mice were killed by cervical dislocation. The brains and livers were rapidly dissected and immediately frozen in liquid nitrogen. These organs were minced and the minced tissue was divided into halves for each animal. Half of the tissue from each brain and liver was processed for RNA extraction and the other half for protein extracts for enzymatic assays.

\section{(f) RNase mapping}

The dissected mouse brains and livers were homogenized in $6 \mathrm{M}$ guanidium isothiocyanate $/ 5 \mathrm{mM}$ sodium citrate $\mathrm{pH} 7.0 / 0.5 \mathrm{M}$ sodium sarkosyl/0.1 M $\beta$-mercaptoethanol using a Dounce homogenizer. Cytoplasmic RNA was then extracted from the homogenates as previously described (Chirgwin et al., 1979).

Two different ${ }^{32} \mathrm{P}$-labeled antisense RNA probes were synthesized from the SP64 plasmids containing normal human hprt cDNA fragments as templates (see Fig. 2). Transcription was performed according to the manufacturer's recommendations, except 3 $\mathrm{mCi} / \mathrm{ml}$ of $\left[\alpha^{-32} \mathrm{P}\right]$ GTP $(800 \mathrm{Ci} / \mathrm{mmol})$ was used in the reaction mixture in place of $\left[\alpha{ }^{32} \mathrm{P}\right] \mathrm{CTP}$. The RNA probe, pHP64-5' was transcribed from the HindIII site to the 5' PstI site of human hprt cDNA. This probe spans 592 bp containing 104 bp of $5^{\prime}$-untranslated sequence and 488 bp of coding sequence. The antisense RNA probe pHP64-3' was transcribed from the 3' PstI site to the HinclI site. This probe is $521 \mathrm{bp}$ and contains $193 \mathrm{bp}$ of $3^{\prime}$-untranslated sequence and 328 bp of coding sequence (see Fig. 2). The labeled RNA probe $\left(10^{6}\right.$ cpm) was hybridized to $50 \mu \mathrm{g}$ of cytoplasmic RNA in $30 \mu \mathrm{l}$ of $80 \%$ formamide $/ 40 \mathrm{mM}$ piperazine$\mathrm{N}$-N1-bis(2-ethane sulfonic acid) (PIPES) $\mathrm{pH}$ 6.4/0.4 M NaCl$/ 1 \mathrm{mM}$ EDTA at $50^{\circ} \mathrm{C}$ for $15 \mathrm{~h}$. The RNA was digested at $30^{\circ} \mathrm{C}$ for $1 \mathrm{~h}$ by $40 \mu \mathrm{g} / \mathrm{ml}$ of RNase A and $2 \mu \mathrm{g} / \mathrm{ml}$ of RNase T1 in $300 \mu \mathrm{l}$ of 10 $\mathrm{mM}$ Tris $\cdot \mathrm{HCl} \mathrm{pH} 7.5 / 5 \mathrm{mM}$ EDTA $/ 300 \mathrm{mM} \mathrm{NaCl}$. After two ethanol precipitations, the RNase-digested RNA was electrophoresed in an $8 \mathrm{M}$ urea denaturing $5 \%$ polyacrylamide gel and autoradiographed (Gibbs and Caskey, 1987). 


\section{RESULTS AND DISCUSSION}

\section{(a) Infection with HSV-HP40}

All mice infected with wt HSV-KOS became ill and died within three days regardless of the infecting dose, including the lowest dose of $2 \times 10^{4}$ pfu per animal. Mice infected with the vector HSV-HP40 showed dose-dependent morbidity and mortality. Mice infected with $2-4 \times 10^{7}$ pfu of HSV-HP40 were ill by day 3 and $81 \%(43 / 53)$ were dead by day 4. At $2 \times 10^{6} \mathrm{pfu}$ of HSV-HP40,16\% (1/6) were dead by day 4 . At $2 \times 10^{5}$ pfu and $2 \times 10^{4}$ pfu, all animals appeared healthy, and none of them died. All but two of these animals were killed by day 7 . These two remained healthy until day 21 when they were killed. RNase mapping analysis was performed on four uninfected and 22 infected mice.

\section{(b) Expression of HPRT mRNA-infected mice}

RNase A mapping analysis using two overlapping human HPRT RNA probes clearly distinguishes human transcripts from endogenous mouse transcripts (Figs. 2-4). Two probes were used because the considerable degree of homology between the mouse and human $\mathrm{HPRT}^{-}$coding sequences results in complex RNase maps that are difficult to interpret. Mouse and human hprt cDNA sequences are less homologous within the $3^{\prime}$ - and $5^{\prime}$-untranslated regions, allowing discrimination between the species-specific mRNAs using smaller probes. The two probes used overlap in the coding region such

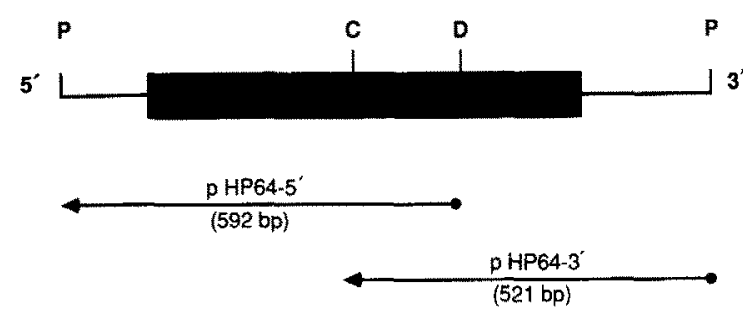

Fig. 2. Construction of human HPRT antisense RNA probes. The 951-bp PstI (P) fragment of human hprt cDNA consists of $10^{4}$ bp of $5^{\prime}$-untranslated sequence, 654 bp of coding sequence (blackened box) and 193 bp of $3^{\prime}$ coding sequence. The 592-bp PstI-HindIII (D) fragment was cloned into pSP64 such that transcription proceeded $3^{\prime}$ to $5^{\prime}$ (D to P), yielding pHP64-5'. The 521-bp Pst I-Hincll (C) fragment was similarly cloned into pSP64 such that transcription ( $P$ to $C$ ) resulted in the antisense probe pHP64-3'.

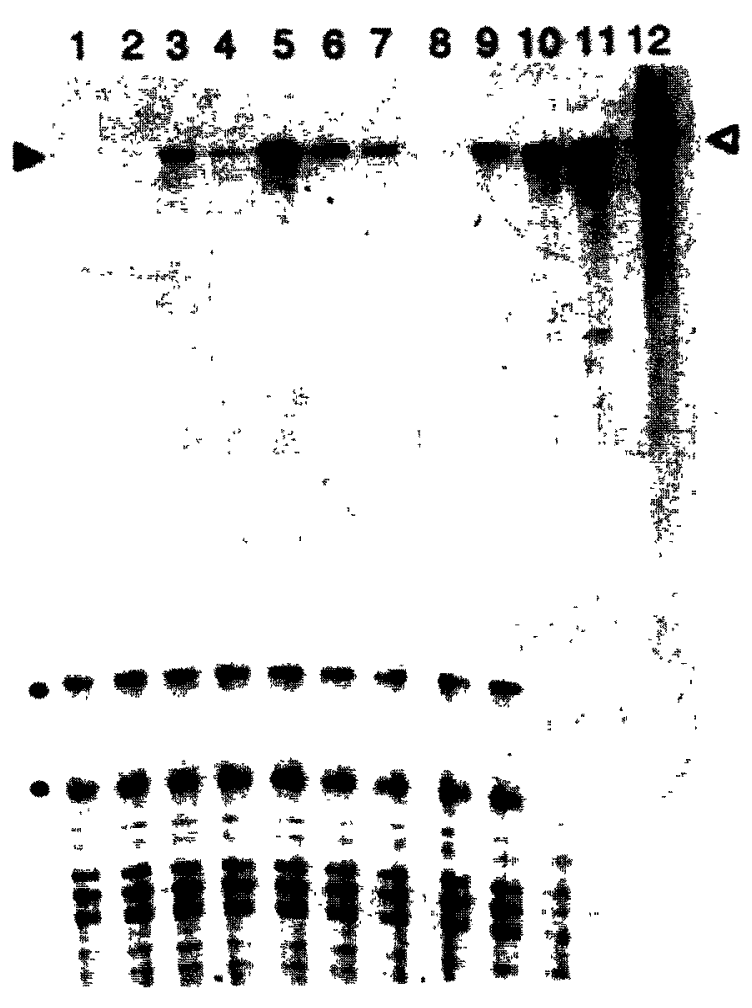

Fig. 3. RNase mapping analysis of RNA from mouse brains using the antisense RNA probe pHP64-3'. Experimental details are provided in MATERIALS AND METHODS, section $f$. Lanes: 1, RNA from an uninfected mouse; 2, RNA from a mouse infected with HSV-KOS $\left(2 \times 10^{7}\right.$ pfu) killed two days postinfection; 3, RNA from a mouse infected with HSV-HP40 $\left(4 \times 10^{7} \mathrm{pfu}\right)$ two days post-infection; 4 , RNA from a mouse infected with HSV-HP40 $\left(2 \times 10^{7} \mathrm{pfu}\right)$ killed two days postinfection; 5, RNA from a mouse infected with HSV-HP40 (4 $\times 10^{7} \mathrm{pfu}$ ) killed three days post-infection; 6, RNA from a mouse infected with HSV-HP40 $\left(4 \times 10^{7} \mathrm{pfu}\right)$ killed two days post-infection; 7, RNA from a mouse infected with HSV-HP40 $\left(2 \times 10^{7} \mathrm{pfu}\right)$ killed two days post-infection; 8, RNA from an uninfected mouse; 9, RNA from a mouse infected with HSVHP40 $\left(2 \times 10^{7} \mathrm{pfu}\right)$ killed three days post-infection; 10, RNA from the lymphoblast cell line, 904, which has normal HPRT activity; 11, RNA from lymphoblast cell line 905 which has normal HPRT activity; 12, undigested probe. The open arrowhead indicates the undigested full-length RNA probe (521 bp). The closed arrowhead represents the RNA probe protected by the normal human HPRT mRNA. The heavy black dots denote RNA probe protected by homologous regions of mouse HPRT mRNA.

that full RNase protection of both probes indicates transcription of the entire human cDNA. The riboprobe pHP64-3' protects a 521-bp fragment of HPRT mRNA from human lymphoblast lines 904 and 905 (Fig. 3, lanes 10 and 11). (The doublet signal 
123456789.1011121374 is

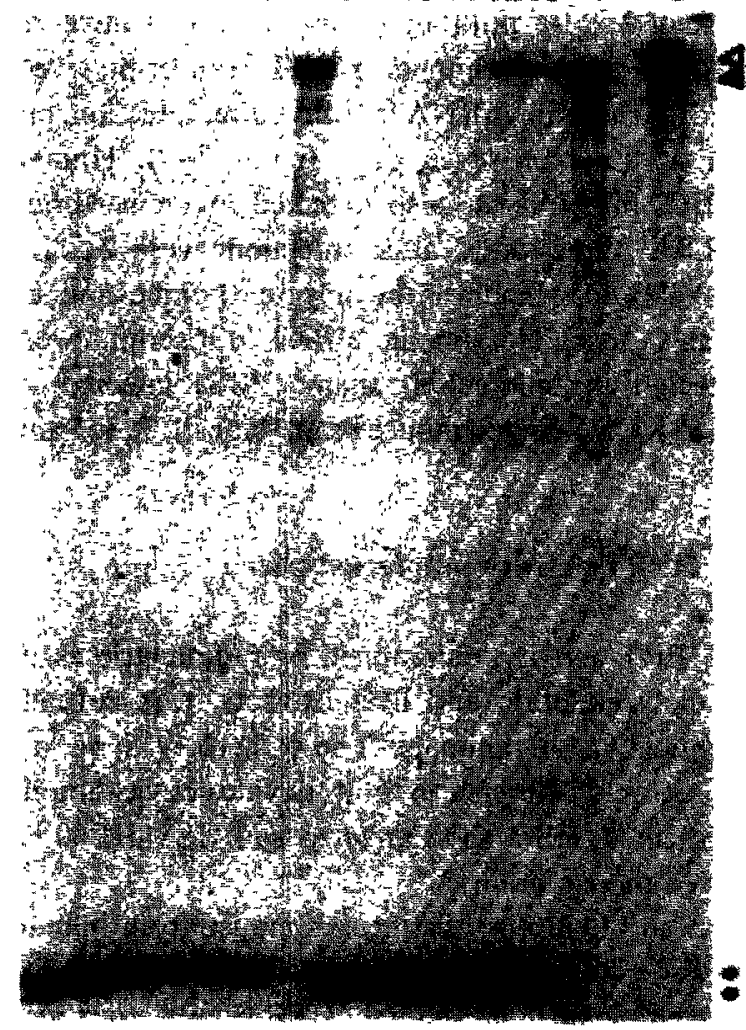

Fig. 4. RNase mapping analysis of RNA from the brains and livers using the RNA probe pHP64-5' in a separate experiment from that shown in Fig. 2. Experimental details are provided in MATERIALS AND METHODS, section $f$. RNA from mouse livers are in lanes 1-6. RNA from mouse brains are in lanes 8-13. Lanes: 1-3, mRNA from livers of uninfected mice; $4, \mathrm{mRNA}$ from liver of mouse infected with HSV-KOS $\left(2 \times 10^{7} \mathrm{pfu}\right)$ and killed two days post-infection; 5, mRNA from liver of mouse infected with HSV-HP40 $\left(4 \times 10^{7}\right.$ pfu), killed two days postinfection; $6, \mathrm{mRNA}$ from liver of mouse infected with HSV-HP40 $\left(2 \times 10^{7} \mathrm{pfu}\right)$, killed two days post-infection; 7 and 14, mRNA from human lymphoblast line $904 ; 8-10$, mRNA from uninfected mouse brains; 11, mRNA from brain of mouse infected with HSV-KOS $\left(2 \times 10^{7} \mathrm{pfu}\right)$, killed two days post-infection; 12 , mRNA from brain of mouse infected with HSV-HP40 (4 × $10^{7}$ pfu), killed two days post-infection; 13, mRNA from brain of mouse infected with HSV-HP40 $\left(2 \times 10^{7} \mathrm{pfu}\right)$, killed two days post-infection; 15 , undigested probe pHP64-5'. The open arrowhead indicates the undigested full-length RNA probe. The closed arrowhead indicates the RNA probe fully protected by the normal human HPRT mRNA (approx. 592 bp). The dots indicate mouse HPRT-specific bands.

seen in these lanes is an artifact resulting from the probe construction. The hprt cDNA used to construct the RNA probes pHP64-3' and pHP64-5' as well as HSV-HP40 was cloned by poly(dG) tailing.
Thus, the antisense probe pHP64-3' has a poly(dG) tail which is somewhat resistant to RNase $A$ and T1 digestion. This results in two 'fully protected' bands when HPRT mRNA from control cells (lymphoblasts) is hybridized to this probe. The larger $M_{\mathrm{r}}$ band is the incompletely digested poly(dG)-tailed hybrid. Since HSV-HP40 also contains these tails, the virally encoded message is completely complementary to the probe. Thus, hybrids of viral encoded HPRT mRNA and pHP64-3' are a single band of the higher $M_{\mathrm{r}}$.) The 521-bp band is not present in mRNA from uninfected mouse brain, although two prominent mouse-specific bands and multiple nonspecific bands are present (Fig. 3, lanes 1 and 8). Thus, the appearance of the 521-bp band corresponds to expression of human HPRT mRNA. This band is absent in mRNA from mouse brain infected with the wt virus, HSV-KOS (lane 2) but is present in mouse brain mRNA from animals infected with HSV-HP40 (lanes 3-7 and 9). The uniform intensity of mouse-specific bands in uninfected mRNA samples as well as samples from mice infected with cither HSV-KOS or HSV-HP40 indicates equivalence of the amount of mRNA in each assay as well as the absence of any negative impact of HSV infection on endogenous mouse brain mRNA levels. It is also apparent that human HPRT mRNA is expressed in a manner dependent upon the infecting dose of virus and duration of infection.

Similar results were obtained using the RNA probe pHP64-5' with mRNA extracted from mouse brain (Fig. 4, lanes 8-13). However, no human HPRT mRNA was detected in mRNA extracted from the livers of mice infected with HSV-HP40 that had human HPRT transcripts in brain samples (compare lanes 5 to 12, and 6 to 13 in Fig. 4). These data, taken together, indicate that the entire hprt cDNA contained within HSV-HP40 was transcribed in the brains, but not in the livers, of mice infected with this vector.

Infecting doses of $2-4 \times 10^{7}$ pfu of HSV-HP40 resulted in considerable mortality among infected animals, although fewer animals infected with HSVHP40 died than did those infected with HSV-KOS at comparable doses. Survival was better at lower viral doses. To assess human hprt cDNA transcription in mice with non-lethal HSV infection, mice were infected with lower doses of HSV-KOS and HSV-HP40 (Fig. 5). No expression was detected at 


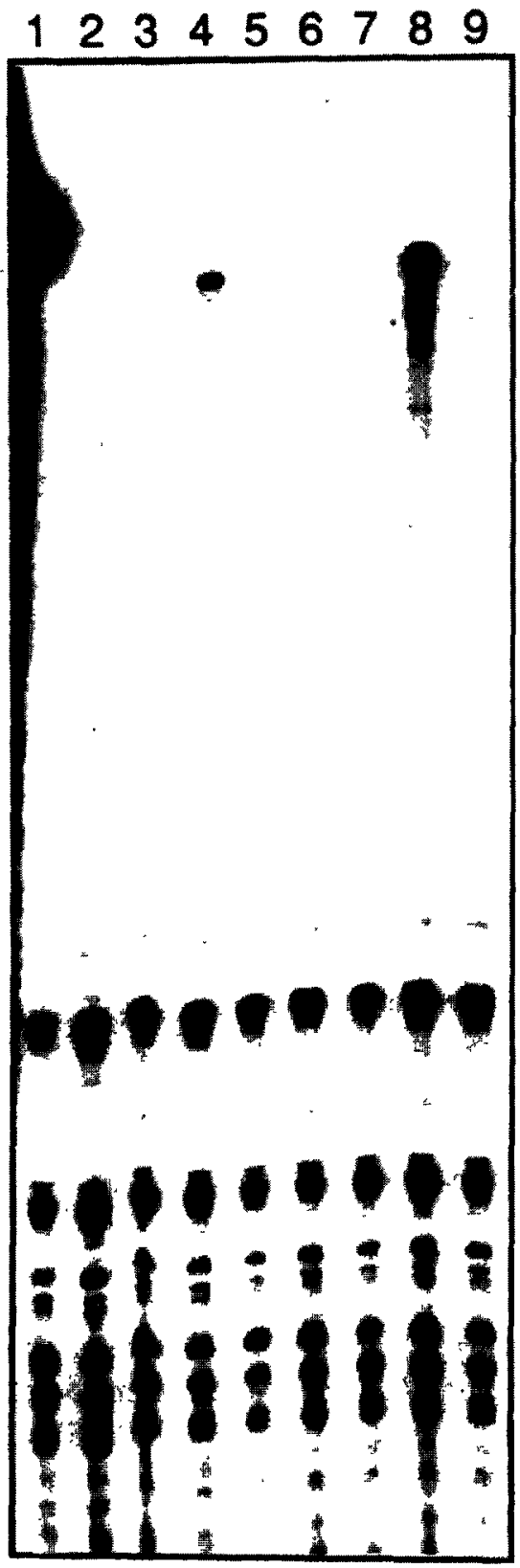

Fig. 5. RNase mapping analysis of RNA from mouse brains using the antisense probe pHP64-3'. Experimental details are provided in MATERIALS AND METHODS, section $f$. Lanes: 1, RNA from an uninfected mouse; 2 , RNA from a sham-infected (PBS) mouse; 3, RNA from a mouse infected with $2 \times 10^{6}$ pfu of HSV-KOS, killed at day $3 ; 4$, RNA from a mouse infected with $2 \times 10^{6}$ pfu HSV-HP40, killed on day $3 ; 5$, RNA from a mouse infected with $2 \times 10^{4}$ pfu HSV-KOS, killed at day 5; 6, RNA from a mouse infected with $2 \times 10^{4} \mathrm{HSV}-\mathrm{HP} 40$ killed at day 3 ; 7 , RNA from a mouse infected with $2 \times 10^{5}$ pfu HSV-KOS killed at day $3 ; 8$, RNA from a mouse infected with $2 \times 10^{5}$ pfu HSV-HP40, killed at day 5; 9, RNA from a mouse infected with $2 \times 10^{5}$ HSV-HP40, killed at day 7 . days 3 and 5 after infection with HSV-HP40 at a dose of $2 \times 10^{4}$ pfu (lanes 5 and 6). At an infecting dose of $2 \times 10^{5}$, human HPRT transcripts were detected in brain mRNA five days after infection, but not at three or seven days (lanes 7-9). Human HPRT mRNA was also detected in mouse brain mRNA three days after infection with $2 \times 10^{6}$ HSV-HP40, which was the only time point examined at this dose. No human HPRT transcripts were detected in uninfected, sham (PBS) infected or HSV-KOS-infected mouse brain (lanes 1, 2, 3, 5 and 7).

\section{(c) HPRT activity in infected mice}

HPRT activity, determined by radiometric assay of dialyzed brain and liver extracts, was virtually identical in all animals. Thus, there was no demonstrable difference in total enzyme activity among uninfected, HSV-KOS infected and HSV-HP40 infected mouse brains.

In an attempt to distinguish mouse from human HPRT activity in these extracts, immunoprecipitation employing anti-human HPRT antiserum was performed. The results were again equivocal (Table I). Although a slightly higher percentage of HPRT activity was precipitated from extracts of infected brain, the absolute amount of HPRT activity precipitated as measured by the radiometric assay (i.e., as cpm) was nearly identical in all samples. Thus, these data cannot be interpreted as demonstrating the expression of human HPRT protein or activity.

Immunoblot analysis yielded similar results for two reasons. First, in native PAGE, human and mouse HPRT show identical migration under the conditions employed. Secondly, on immunoblots, anti-human HPRT antiserum cross-reacted with mouse HPRT even at antiserum dilutions of 1:5000 (data not shown). Thus, this technique could not discriminate human from mouse HPRT.

These results demonstrate the transfer and expression of human gene sequences in mouse brain after in vivo infection with recombinant $\mathrm{HSV}-1$ derived vectors. Human HPRT mRNA transcripts were detected at levels comparable to or in excess of endogenous mouse HPRT mRNA in brains infected with HSV-HP40. Expression of human HPRT mRNA was detected dependent on the infecting dose of 
TABLE I

Inmunoprecipitation of HPRT activity from mouse brain extracts

\begin{tabular}{lc}
\hline Treatment $^{\mathrm{a}}$ & $\begin{array}{l}\% \text { HPRT activity } \\
\text { precipitated }^{c}\end{array}$ \\
\hline Human control (GM5580) & 90.4 \\
Uninfected mouse & 3.9 \\
& 8.5 \\
Infected & \\
HSV-HP40 $2 \times 10^{7}$ pfu (day 2) & 10.3 \\
HSV-HP40 $2 \times 10^{7}$ pfu (day 2) & 12.2 \\
HSV-HP40 $2 \times 10^{7}$ pfu (day 4) & 10.0 \\
\hline
\end{tabular}

a See MATERIALS AND METHODS, section $\mathbf{f}$.

- Time of killing after infection is in parentheses.

c Mouse brains were homogenized in $10 \mathrm{mM}$ Tris $\cdot \mathrm{HCl} \mathrm{pH} 7.4$ by a Dounce homogenizer. After centrifugation of the homogenates to remove membranes and nuclei, the supernates were recovered for analysis. Anti-human HPRT antiserum (Wilson

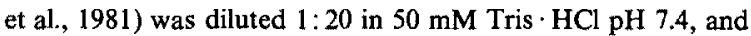
$0.5 \mathrm{mg} / \mathrm{ml}$ of BSA fraction V. Antiserum $(5 \mu \mathrm{l})$ was added to 45 $\mu 1$ of mouse brain or liver extract adjusted to $30 \mu \mathrm{g}$ of total protein (final antiserum dilution was $1 / 200$ ). Previous studies demonstrated that at this dilution, less than $10 \%$ of the HPRT activity in mouse brain extracts was precipitated while $90 \%$ of human HPRT activity was precipitated from extracts of GM558 cells (data not shown). Identical reactions were prepared with 5 $\mu 1$ of antiserum dilution buffer only. Samples were incubated at $37^{\circ} \mathrm{C}$ for $30 \mathrm{~min}$ and rotated overnight at $4^{\circ} \mathrm{C}$. After overnight incubation, $5 \mu \mathrm{l}$ of $10 \%$ staphylococcal protein A (Igsorb) were added to each sample which were incubated at $22^{\circ} \mathrm{C}$ for $10 \mathrm{~min}$, after which they were centrifuged at $4000 \times g$ for $5 \mathrm{~min}$. Each supernatant $(50 \mu \mathrm{l})$ was assayed for HPRT activity by the method of Holden and Kelley (1978). Extracts of uninfected and infected rat brains were electrophoresed through $10 \%$ polyacrylamide gels under nondenaturing conditions. After electrophoresis, proteins were electroblotted onto nitrocellulose filters. Filters were incubated in $1 \%$ nonfat milk, $10 \mathrm{mM}$ Tris $\cdot \mathrm{HCl} \mathrm{pH} 7.4 / 150 \mathrm{mM}$ $\mathrm{NaCl}$ and then with rabbit anti-human HPRT antiserum and probed with staphylococcus [ ${ }^{125}$ I]protein A (Wilson et al., 1981; 1988). Blots were then washed, dried and exposed overnight to Kodak XAR-5 film at $-70^{\circ} \mathrm{C}$.

virus and duration of infection. Furthermore, there was no suppression of endogenous mouse HPRT mRNA or HPRT activity levels after infection with either HSV-KOS or HSV-HP40. Mortality also varied with infecting dose. Infection with wt virus, HSV-KOS, was nearly uniformly lethal. Survival was better in animals infected with HSV-HP40, particularly at lower infecting doses.
Expression of human HPRT mRNA was detected in these infected animals. The course of expression likely parallels viral replication in the brain. Additionally, infection - or at least expression appeared limited to brain: no human HPRT transcripts were detected in mRNA extracted from livers of infected animals.

Human HPRT protein or enzyme activity could not be unequivocally demonstrated. There are two potential explanations for this. First, the techniques employed did not adequately discriminate mouse from human protein. Specifically, human HPRT could not be differentially immunoprecipitated in the presence of endogenous mouse HPRT. Indeed, this might reflect the formation of human-mouse HPRT heterotetramers in vivo in cells in which both mouse and human HPRT monomers were simultaneously synthesized. Such heteromer formation has been previously inferred from data obtained from transgenic mice expressing the human hprt gene (Stout et al., 1985). Additionally, the sensitivity of the immunoprecipitation assay could not be determined and, thus, the detection of a small amount of immunoprecipitable human HPRT against a mouse background might be beyond the limits of this technique. Immunoblot analysis was similarly confounded. Mouse HPRT migrates identically with human HPRT on polyacrylamide gel electrophoresis. Furthermore, there was substantial cross reactivity of antiserum directed against the human protein with the murine protein.

Second, translation of the virally encoded human HPRT mRNA might be less efficient than that of endogenous mRNA. By contrast, in our previous report of expression of human HPRT in cultured rat neuronal cells, we were able to demonstrate expression of active human HPRT (Palella et al., 1988). Expression of protein in vitro but not in vivo has been noted previously in human gene transfer experiments into animal cells using retroviral vectors (Wilson et al., 1988). The basis for this observation is not clear, but may reflect abnormalities in mRNA structure, processing or transport.

These experiments demonstrate the transfer and expression of human gene sequences in brain after in vivo infection with recombinant $\mathrm{HSV}-1$ vectors. They also serve to highlight several potential problems that await resolution in these systems. 


\section{ACKNOWLEDGEMENTS}

The authors gratefully acknowledge the expert secretarial assistance of Ms. Ardith Listeman. This work was supported by U.S. Public Health Service grants DK19045 and DK39834 and the Michigan Chapter of the Arthritis Foundation.

\section{REFERENCES}

Anderson, W.F.: Prospects for human gene therapy. Science 226 (1984) 401-409.

Baringer, J.R. and Sworeland, P.: Recovery of herpes-simplex virus from human trigeminal ganglions. N. Engl. J. Med. 228 (1973) 9593-9596.

Chang, S.M.W., Wagner-Smith, K., Tsao, T.Y., Henkel-Tigges, J., Vaishnar, S., and Caskey, C.T.: Construction of a defective retrovirus containing the human hypoxanthine phosphoribosyltransferase $\mathrm{CDNA}$ and its expression in cultured cells and mouse bone marrow. Mol. Cell. Biol. 7 (1987) 854-863.

Chirgwin, J.M., Przybyla, A.E., MacDonald, R.J. and Rutter, W.J.: Isolation of biologically active ribonucleic acid from sources enriched in ribonuclease. Biochemistry 18 (1979) 5294-5299.

Cook, M.L., Bastone, V.B. and Stevens, J.G.: Evidence that neurons harbor latent herpes simplex virus. Infect. Immun. 9 (1974) 946-951.

Edwards, N.L., Jeryc, W. and Fox, I.H.: Enzyme replacement in the Lesch-Nyhan syndrome with long-term erythrocyte transfusions. Adv. Exp. Med. Biol. 165A (1984) 23-26.

Gibbs, R.A. and Caskey, C.T.: Identification and localization of mutations at the Lesch-Nyhan locus by ribonuclease $A$ cleavage. Science 236 (1987) 303-305.

Hidaka, Y., Palella, T.D., O’Toole, T.E., Tarle, S.A. and Kelley, W.N.: Human adenine phosphoribosyltransferase: identification of allelic mutations at the nucleotide level as a cause of complete deficiency of the enzyme. J. Clin. Invest. 5 (1987) 1409-1415.
Holden, J.A. and Kelley, W.N.: Human hypoxanthine-guanine phosphoribosyltransferase: evidence for tetrameric structure. J. Biol. Chem. 253 (1978) 4459-4463.

Miller, A.D., Jolly, D.J., Friedmann, T. and Verma, I.M.: A transmissible retrovirus expressing human hypoxanthine phosphoribosyltransferase (HPRT): gene transfer into cells obtained from humans deficient in HPRT. Proc. Natl. Acad. Sci. USA 80 (1983) 4709-4713.

Miller, A.D., Eckner, R.J., Jolly, D.J., Friedmann, T. and Verma, I.M.: Expression of a retrovirus encoding human HPRT in mice. Science 225 (1984) 630-632.

Nyhan, W.L., Parkman, R., Page, T., Gruber, H.E., Pyati, J., Jolly, D.J. and Friedman, T.: Bone marrow transplantation in Lesch-Nyhan disease. Adv. Exp. Med. Biol. 195A (1986) $167-170$.

Palella, T.D., Silverman, L.J., Schroll, C.T., Homa, F.L., Levine, $M$, and Kelley, W.N.: Herpes simplex virus-mediated human hypoxanthine-guanine phosphoribosyltransferase gene transfer into neuronal cells. Mol. Cell. Biol. 8 (1988) 457-460.

Seegmiller, J.E., Rosenbloom, F.M. and Kelley, W.N.: Enzyme defect associated with a sex-linked human neurological disorder and excessive purine synthesis. Science 155 (1967) 1682-1684.

Shih, M.-F., Arsenakis, M., Tiollais, P., and Roizman, B.: Expression of hepatitis $B$ virus $S$ gene by herpes simplex virus type 1 vectors carrying alpha- and beta-regulated gene chimeras. Proc. Natl. Acad. Sci. USA 81 (1984) 5867-5870.

Stout, J.T., Chen, H.Y., Brennand, J., Caskey, C.T. and Brinster, R.L.: Expression of human HPRT in the central nervous system of transgenic mice. Nature 317 (1985) 250-252.

Tackney, C., Cachianes, G. and Silverstein, S.: Transduction of the Chinese hamster ovary APRT gene by herpes simplex virus. J. Virol. 52 (1984) 606-614

Wilson, J.M., Baugher, B.W., Landa, L. and Kelley, W.N.: Human hypoxanthine-guanine phosphoribosyltransferase: purification and characterization of mutant forms of the enzyme. J. Biol. Chem. 256 (1981) 10306-10312.

Wilson, J.M., Johnston, D.E., Jefferson, D.M. and Mulligan, R.C.: Correction of the genetic defect in hepatocytes from the Watanabe heritable hyperlipidemic rabbit. Proc. Natl. Acad. Sci. USA 85 (1988) $4421-4425$. 